\title{
A STUDY ON SUPPLY CHAIN AND SOCIAL MEDIA PLATFORMS WITH SPECIAL REFERENCE TO THE CLOTHING BRAND ZARA
}

\author{
Ms. Shweta Singh
}

\begin{abstract}
The purpose of this research paper is to find how the factors like the social media platforms, and the supply chain management are actually responsible towards the growth of the clothing brand Zara. The brand follows the strategy of minimal advertisement, where they are able to maintain their position in the market. Zara is found to use marketing of its products mainly through its influencers, social media platforms, its supply chain management, and timely availability of the products in such changing trends. Still, it has a fierce competition today with many other clothing brands, therefore they may need to engage in more direct advertisement, and promotion. The research covers different factors within the social media platforms as well. The findings revealed more in-depth knowledge and understanding of the selected factors of Zara's growth with both primary and secondary research done, and what their customers want their brand to improve in the areas to have a consistent leading position in the fashion retail market and will reveal how these factors are more effective for Zara's growth from various perspectives.
\end{abstract}

Keywords: Zara, Marketing Strategies, Social Media Platforms, Supply Chain Management, Growth Factors.

\section{* INTRODUCTION}

Today the clothing brand Zara is one of the most popular fast fashion brands which has expanded quickly in the worldwide retail fashion market. This brand was founded by Amancio Ortega in 1975, it is the flagship chain store of the Inditex group, that is the world's largest clothing retailer contributing maximum towards their overall revenue. This fashion group also owns several other brands such as the Pull\&Bear, the Massimo Dutti, Bershka, Stradivarius, Oysho, Zara Home and few others as well. Today, the company operates over more than 2,220 stores and has its presence in around 88 countries. Also, Zara has consistently acted as a pioneer in fast fashion-based on an effective supply chain management. Their aim is to enrich the overall customer's experience and also are at the heart of a unique business model, that includes the design, production, distribution and also the sales through their extensive retail network that is their efficient supply chain management. Also, Zara had increase in its revenues to Rs. 1570.54 crores as well as its profit to $45.5 \%$, as per July,2020 (moneycontrol, 2020). So, this research paper aims to develop and analyse the brand Zara to explore the factors responsible for its growth that are its supply chain management, and its social media platforms. To begin with, the research paper is going to analyse the overall business model of Zara to have an in-depth understanding of both these factors with clarity. In addition, it will also help in finding if there is any improvement if required in these two specific areas. As a whole, this paper will discuss the market application of Zara's growth today in terms of its social media platforms and the supply chain management. 


\section{* $\quad$ RESEARCH PROBLEM}

Zara is already a famous fashion clothing brand all around the world. How it has been able to position itself in the mind of the customers. The need came out to know how it is able to maintain it constantly with its supply chain management and its social media platforms, taking these factors as responsible for its growth in-depth? The need arises to address the Research Problem as to know how Zara is able to have such good market presence, in spite that they do much minimal advertising? and to explore them in more detail. The study will be done with the help of a questionnaire or the primary data, and secondary data too, so to have more clear understanding on how the customers are able to get attached to the brand so easily.

\section{* OBJECTIVES}

1) To Understand the Supply Chain Management of the Clothing Brand Zara as a Growth Factor.

2) To Understand the Social Media Platforms of the Clothing Brand Zara among the Youth as a Growth Factor.

\section{* $\quad$ HYPOTHESIS}

1) H0- There is no Significant Impact of the Supply Chain Management as a growth factor for the Clothing Brand Zara.

H1- There is a Significant Impact of the Supply Chain Management as a growth factor for the Clothing Brand Zara.

2) H0- There is no Significant Impact of the Social Media Platforms of the Clothing Brand Zara among the Youth as a growth factor.

H1- There is a Significant Impact of the Social Media Platforms of the Clothing Brand Zara among the Youth as a growth factor.

\section{* LITERATURE REVIEW}

This analysis was done on (ZARA CASE STUDY, 2002) by Devangshu Dutta for its reasons of Zara efficiency clearly, Zara is riding its two of the winning retail trends, firstly to being in fashion and secondly, to low the prices like Short Lead Times, keeping Up With Fashion, Zara not only reduces its exposure to any single product but also creates an artificial scarcity, ownership and control of production and instead of making more quantities per style, Zara produces more styles, roughly 12,000 a year. Thus, even if a style sells out very quickly there are other styles waiting to take place, also rather than concentrating on the forecasting accurately, it has developed its business 
Towards Excellence: An Indexed, Refereed \& Peer Reviewed Journal of Higher Education / Ms. Shweta Singh / Page 226-249

around reacting swiftly, keeping costs down, etc. But still in spite of all these studies it was not properly found the actual factors on how the Zara is able to maintain a great market presence and high sales having only a few percentages of their investment on Advertisement.

Another paper showed that Zara seems to follow the classic stage models and how it leads to efficient process of internationalization of Zara with low advertisement and how it is able to expand itself so fast. Even though they need to be more careful for market selection and other marketing strategies applied by them. This study was done on (The role of market orientation on company performance through the development of sustainable competitive advantage: The Inditex-Zara case, 2003) by Ruth Avendano and Andres Mazaira.

Further study was done to know the effectiveness of having a more customer centric approach to marketing in order to achieve long-term strategic success and market leadership in the fashion industry by (Viardot, 2013) on How Zara has revolutionized the fashion industry and become a worldwide leader. With the help of agile supply chain strategy's, customers centric marketing strategy, the central role of the stores in building trust. Still they are going to face the challenges when customer centric marketing strategy is met when confronted with the expansion of the online market.

Also, study done in (Irma Shyle and Flutura Gjana, 2014) on Zara amongst fast fashion brands about the brand is strong when they have good brand equity and the key factor that can bring to the company the higher profits, brand extension opportunities and protection against competitors. The research was on Zara works towards becoming a strong brand. By using an international branding strategy, Zara not only increases its financial position, but also reinforces its strategic position in the world. Therefore, the results were that they were not much influenced by brand awareness/association and were a little bit low compared with brand loyalty and perceived quality.

Today, Zara is one of the most famous retail fashion stores, which expanded quickly in the worldwide fashion market under its parent company Inditex. Zara has a high customer base even though they are not much involved in the advertisement. So, there were many other researchers/authors who did their research on Zara from various perspectives. The product of the clothing brand Zara looks like a highend fashion, but it's not actually much not expensive. It is identified that there are five main reasons. Firstly, Zara's design is based on the demand of customers and also to meet people's need for individuation. The second being that Zara provides the unique product by limited run and Zara always updates its new products quickly in all their stores. The third is Zara has a young design team who are passionate and innovative in their approach. In addition, Zara also gathers the data by PDA (personal detail analysis) via store POS (Point-of-sale) system to analyse their customer's behaviour. The last reason is that of Zara's unique manufacturing as well as the logistic process as per the analysis done by Kerui Liu of Monash University on (ZARA-Case Study Analysis, 2015). Therefore, it was found that Zara uses a vertical-oriented system that can speed up the overall process and also lowers the cost.

In another analysis done by (Joseph, 2015) on Integrated Marketing Communications Communication Portfolio on ZARA), about Zara's different communicative technique that it incorporates into its brand image, identity and concept. They observe their customers buying behaviour, produces where it sells, also the integrated marketing campaign called where people had started getting attracted to bloggers, followers and readers. The gap found was that it does not actively engage through social media and that it does not incorporate the $7 \mathrm{P}$ 's of marketing, while the problem lies in here is communication. Suggestions provided were using the Transmedia Planning by using 
Towards Excellence: An Indexed, Refereed \& Peer Reviewed Journal of Higher Education / Ms.

Shweta Singh / Page 226-249

each medium to the fullest, more Persuasion and more Attraction with customers to enhance the brand value.

The study done by the authors (Roederer, 2016) on Zara: The international success of fast-moving fashion, that success of Zara depends upon its Brand positioning but has a challenge as it differs from country to country and also the product policy offering range for all the "women", "men" and "children" and even covers all age categories. The brand's strategy of this brand is to adapt to all trends. While Zara's main competitors, Gap and H\&M, spend some amount of their turnover in advertising, Zara invests far less in this domain, hence it has the expression of "no marketing" often associated with the Zara brand. And Its sales outlet is considered the most powerful means of promoting the brand. In terms of relationship marketing Zara is doing well, but has a limitation also that its online sales should be progressively extended to all other markets. Also, it was analysed that Zara does not apply the same pricing policy in all countries where its products are sold.

The results of Zara in 2017 were amazingly remarkable. Its sales were found to be increased and its gross profit as well, few percentages higher as compared to 2016. It was found that the company will continue to have prosperity in the future as well. However, they should be more proactive in fixing their labour issues among others, in order to potentially avoid a crisis that might affect the company as per the study done by (Kato, 2018) from Hult International Business School on Analysis of the Keys to Zara's (Inditex) Successful Business Model.

Another study was done on implementation of the technology in business should be made on the clothing brand ZARA done by (ARTEMIOU, 2019) on Does having technology in a business enhance or hurt their chances for success?", in order to make the customer experience more amazing, they are using holograms to enrich the customers experience where they can easily see themselves in that outfit without having to try it and also installation of the vending machines to ease up the payment procedure. But they still need to keep on updating and properly utilize it before losing it to the other competitive brands.

Also, analysis on Zara was made on (Zara - Marketing Plan) by Alan Poso Rosadio, was to make minimal use and investment in IT. The competitive advantage the Zara has over its competitors is not so much due to the use of IT, but because of its quick response to the changing market. Also, Zara needs to examine, analyse and compare the tangible/quantitative costs and benefits as well as the intangible/qualitative costs and benefits of the old system and its new system which further needs to be analysed.

Therefore, on a concluding note this research will help to find the factors responsible for Zara's success and how its minimal marketing strategies and indirect advertisement helps still maintain the position it has today and the current level of good customer base as well. Still by understanding it can be found that in most studies the major factors are not mentioned apart from that they are able to create enriched customer experience, although, Zara has maintained its leading position in the fashion clothing because of their effective supply chain management, thereby lower prices, quick response system, choice and easy availability of choices. Even they have not been very effective when it comes to advertisements in different countries. Zara also is able to make effective use of the influencers and bloggers. Zara is also using their hologram efficiently, but, other study states that they need to be more proactive with the future challenges.

\section{* $\quad$ RESEARCH GAP}


Towards Excellence: An Indexed, Refereed \& Peer Reviewed Journal of Higher Education / Ms.

Shweta Singh / Page 226-249

To explore both Supply Chain management and especially, Social Media Platforms of Zara, as not much explored properly in-depth in the previous researches. To know how Zara, grow in spite of doing such minimal advertising. To have more larger sample size.

\section{* RESEARCH METHODOLOGY}

The Research Method used are Secondary Research done with the help of Research Journals and Articles, whereas, Primary Research by the Survey Method, i.e. Structured Questionnaire, with sample size of 175 respondents.

The Research Design is basically Descriptive Design, as the help of the previous research papers is involved to form a base, and found that gap which can be covered in this paper to arrive at a conclusion.

The Sampling Design is the Convenience Sampling as it was convenient to target the respondents via WhatsApp, Instagram and Facebook.

Statistical Tools used are the Reliability test, Factor Analysis, Cross-tabs, and Regression \& Correlation Analysis.

\section{* ANALYSIS AND INTERPRETATION}

1) A)
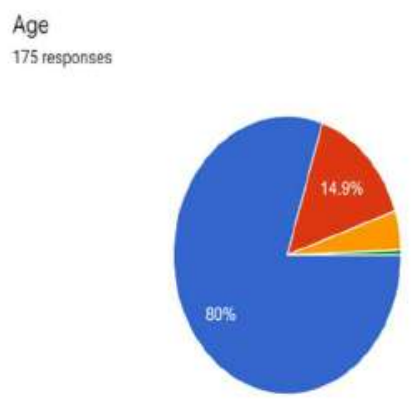

B)
As per the pie chart there are around $80 \%$ respondents from age-group 18 25 , and next around $14.9 \%$ from $26-35$ years. 
Towards Excellence: An Indexed, Refereed \& Peer Reviewed Journal of Higher Education / Ms.

\section{Shweta Singh / Page 226-249}

Gender

175 responses

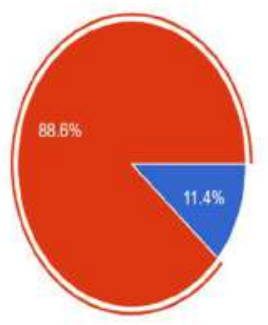

C)

Which category you belong to?

175 responses

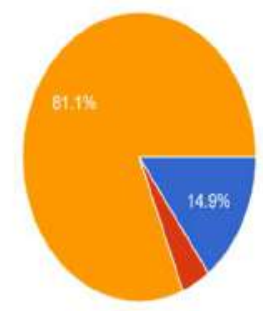

D)

Q.1 On what basis do you like the brand Zara most? 175 responses

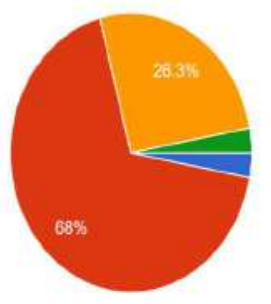

As per the pie chart mostly are the female respondents with $88.6 \%$ and male with $11.4 \%$.
Most of the respondents are the students with $81.1 \%$, then the earning with around $14.9 \%$.
As per the chart $68 \%$ respondents like the Zara brand on the basis of its Quality, then $26.3 \%$ for its Collections. 
Towards Excellence: An Indexed, Refereed \& Peer Reviewed Journal of Higher Education / Ms.

\section{Shweta Singh / Page 226-249}

E)

Q.2 Who do you think is the major Competitor of Zara?

175 responses

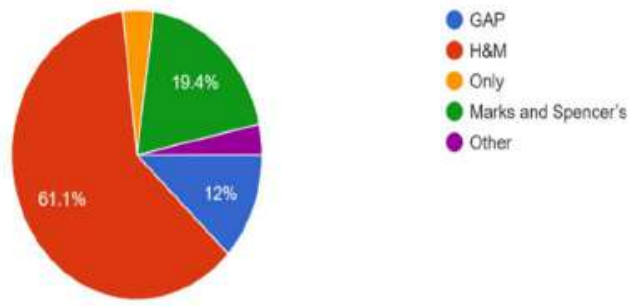

As per the respondents the major competitors of the Zara are H\&M with $61.1 \%$, then the Mark's and Spencer's with $19.4 \%$.

F)

Q.3 On what areas you think the brand Zara needs to improve? 175 responses

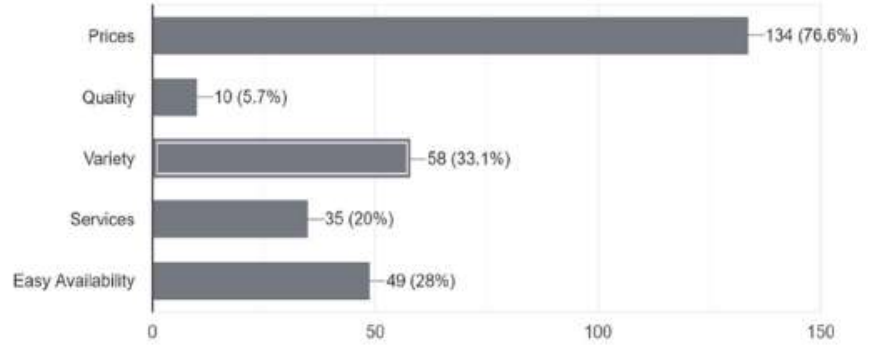

As per age the graph of $18-25$ years including thinks that the Zara needs to improve on its Prices $(76.6 \%)$, followed by its Variety (33.1\%), and want improvement in easy availability $(28 \%)$ as well.

G)

Q.4 To what level are you able to associate yourself with the content shared on Zara's Social Media Platforms? ( on the basis of scale) (1-2 as "Less Rel...as "Somewhat relatable", 8-10 as "Highly Relatable") 175 responses

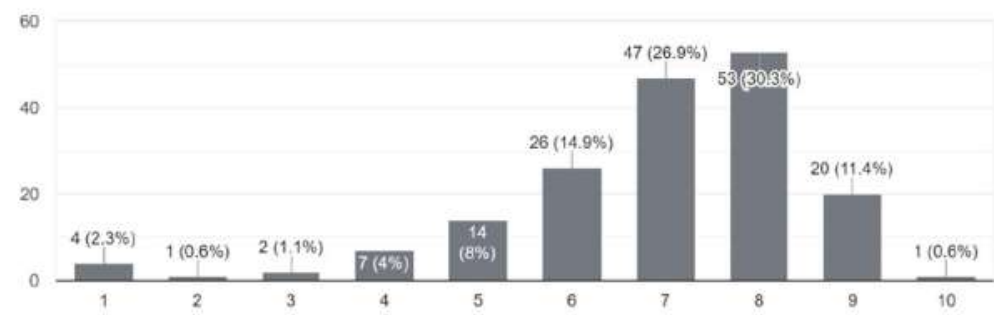

As per the above bar graph It is found that around more $26 \%$ $30.3 \%$ of the respondents are able to relate themselves, and more than $11.4 \%$ highly able to relate themselves to content that is being shared on the social media platforms of the brand Zara. 
Towards Excellence: An Indexed, Refereed \& Peer Reviewed Journal of Higher Education / Ms.

\section{Shweta Singh / Page 226-249}

H)

Q.5 Have you ever got any complaints or queries settled through the Social Media Platforms of the clothing Brand Zara?

175 responses

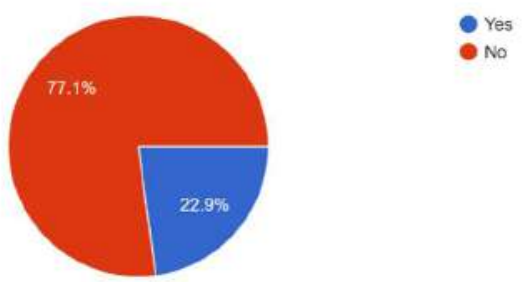

As per the pie chart around $77.1 \%$ respondents have not filed any complaint, while around $22.9 \%$ have placed complaint or queries from social media platforms of Zara.

I)

Q.6 How did you get to know about the clothing Brand Zara? 175 responses
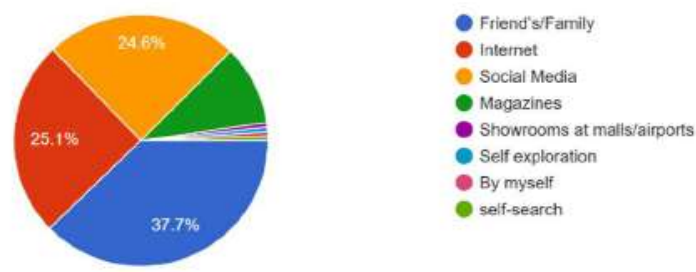

As per the pie chart the respondents knew about the Zara from Friend's/Family with $37.7 \%$, from Internet with $25.1 \%$, then Social Media with $24.6 \%$, whereas some of them from their own self search, selfand Malls. exploration and at Showrooms

J)

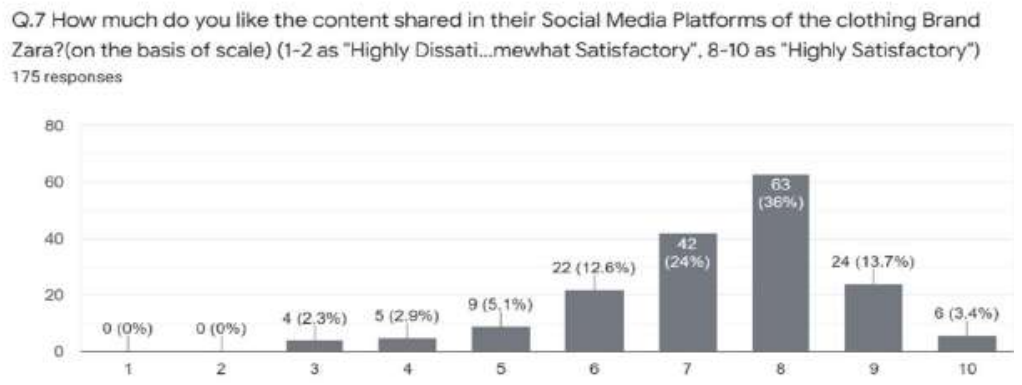

Around between 24\%-36\% respondents are somewhat satisfactory with the content shared on the social media platforms of Zara, and more than $15 \%$ are highly satisfied. 
Towards Excellence: An Indexed, Refereed \& Peer Reviewed Journal of Higher Education / Ms.

\section{Shweta Singh / Page 226-249}

$\mathrm{K})$

Q.8 What is the frequency of your visit to the Zara's official Social Media Platforms? 175 responses

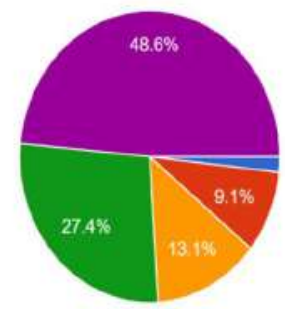

As per the chart the $48.6 \%$ of the respondents visit the social media platform of Zara, while $27.4 \%$ visit on monthly basis, and then $13.1 \%$ visit within $2-3$ weeks.

L)

Q.9 Do you like the latest collection and variety of Zara brand? (on the basis of scale) (1-2 as "Highly Dissatisfactory", 3-4 as "Somewhat Dissatisfactory"...what Satisfactory", 8-10 as "Highly Satisfactory") 175 responses

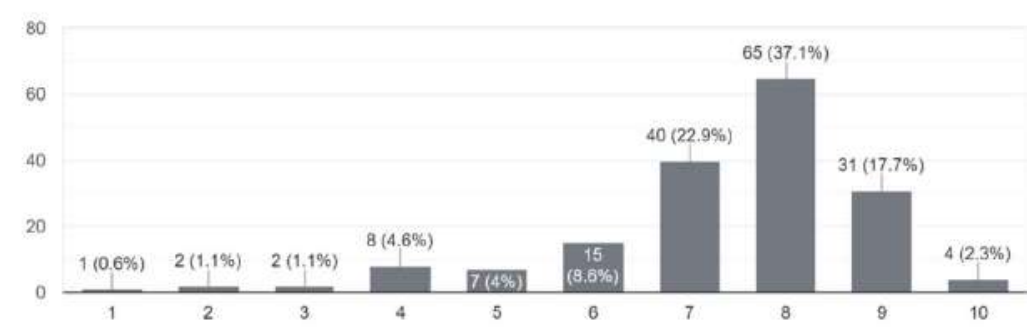

As per the graph between 5\%$25 \%$ respondents are somewhat satisfied with the collection and variety of the brand Zara, whereas more than $37.1 \%$ of the respondents are highly satisfied by its collection and variety. 
Towards Excellence: An Indexed, Refereed \& Peer Reviewed Journal of Higher Education / Ms.

\section{Shweta Singh / Page 226-249}

M)

Q.10 What is your opinion about the Zara's official Social Media Platforms on the basis of following factors? (basis on a scale)( 1 being "Highly Dissatisfactory", 2 as "..., 4 as "Somewhat Satisfactory", 5 as "Highly Satisfactory")

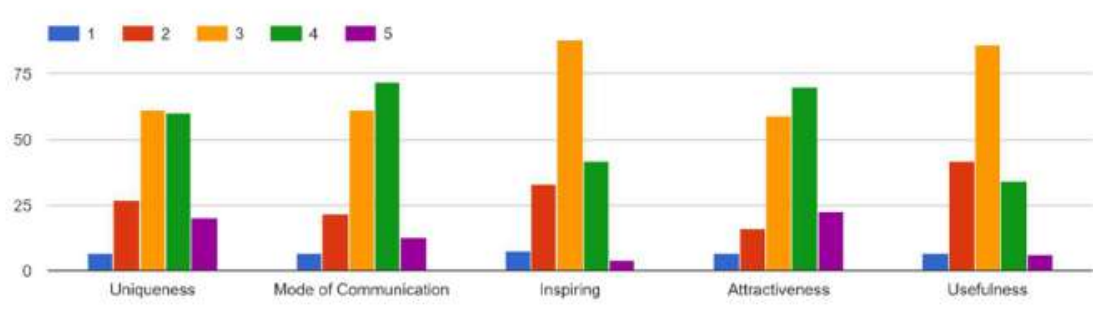

As per the graph for the graph showing viewpoint of the respondents from the various factors for the social media platforms of Zara, respondents mostly think it is Unique, good mode of communication, little Inspiring and mostly Attractive.

N)

Q.11 Are you likely to shop via the Social Media Platforms of Zara?

Around $44.6 \%$ of the

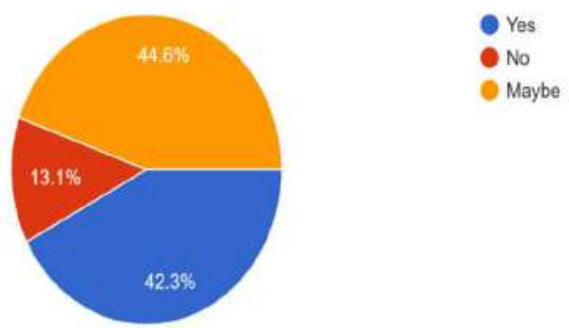
respondents are neutral towards shopping via the social media, whereas $42.3 \%$ are sure to shop from the social media platforms of Zara.

O)

Q.12 What do you like the most about the Zara's Sales Personnel on the following basis?

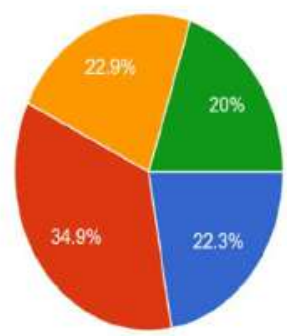

- Greetings

- Way of Presentation

Services

Interest shown by them
As per the pie chart respondents like the personnel of the Zara with mostly for their Way of Presentation with 34.9\%, then $22.9 \%$ for Services, while, $22.3 \%$ for their Greetings and 205 for the Interest shown by them. 
Towards Excellence: An Indexed, Refereed \& Peer Reviewed Journal of Higher Education / Ms.

\section{Shweta Singh / Page 226-249}

P)

Q.13 How likely are you going to recommend the brand Zara to others? (on the basis of scale) (( $1-2$ as "Less Likely", 3-4 as "Somewhat Less Likely", 5 as..., 6-7 as "Somewhat Likely", 8-10 as "Highly Likely") 175 responses

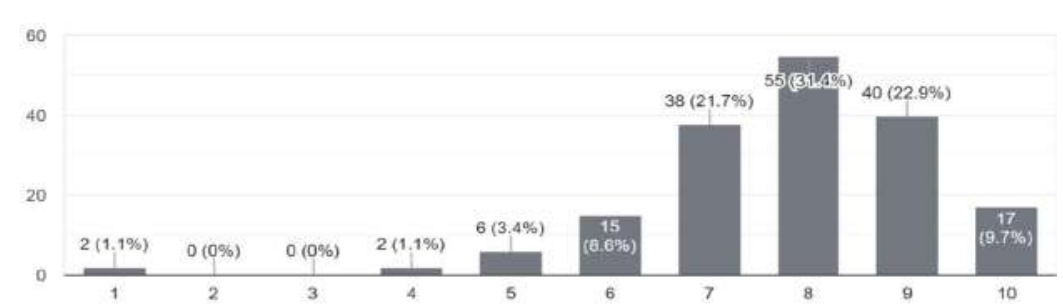

Around $\quad 8.6 \%-21.7 \%$ respondents are somewhat likely to recommend the brand Zara to other, and around $60 \%$ are very likely to recommend the brand to others.

\section{A) RELIABILITY TEST}

\begin{tabular}{|c|c|c|}
\hline \multicolumn{3}{|c|}{ Reliability Statistics } \\
\hline $\begin{array}{c}\text { Cronbach's } \\
\text { Alpha }\end{array}$ & $\begin{array}{c}\text { Cronbach's } \\
\text { Alpha Based } \\
\text { on } \\
\text { Standardized } \\
\text { Items }\end{array}$ & Nof items \\
\hline .847 & .862 & 9 \\
\hline
\end{tabular}

\section{Scale Statistics}

\begin{tabular}{c|r|r|r} 
Mean & Variance & Std. Deviation & N of Items \\
\hline 45.55 & 56.400 & 7.510 & 9 \\
\hline
\end{tabular}

\section{Summary Item Statistics}

\begin{tabular}{lr|r|r|r|r|r|r} 
& Mean & Minimum & Maximum & Range & \multicolumn{1}{c}{$\begin{array}{c}\text { Maximum / } \\
\text { Minimum }\end{array}$} & Variance & N of Items \\
\hline Item Means & 5.061 & 2.931 & 7.815 & 4.884 & 2.667 & 4.824 & 9 \\
\hline Item Variances & 1.548 & .709 & 2.824 & 2.115 & 3.982 & .727 & 9 \\
\hline Inter-Item Correlations & .411 & .231 & .655 & .424 & 2.839 & .015 & 9 \\
\hline
\end{tabular}


Towards Excellence: An Indexed, Refereed \& Peer Reviewed Journal of Higher Education / Ms.

\section{Shweta Singh / Page 226-249}

As the Cronbach's Alpha is greater than 0.6 that is 0.847 , hence, it has a good reliability among the data by conducting on the Likert Scale factors on around 9 items. The next table shows the mean and standard deviation of all the 9 items. The next is the Correlation Matrix Table, showing level of correlation between each item in each cell where all the values below and above the diagonal $(=1)$ are positively correlated.

\section{B) FACTOR ANALYSIS}

\section{KMO and Bartlett's Test}

\begin{tabular}{|c|c|c|c|c|c|c|c|c|c|}
\hline \multirow{4}{*}{ Brandassociation } & \multicolumn{5}{|c|}{ Kaiser-Meyer-Olkin Measure of Sampling Adequacy. } & \multirow{2}{*}{\multicolumn{2}{|c|}{$\begin{array}{r}.836 \\
762.492\end{array}$}} & \multirow{3}{*}{ Usefulness } & \multirow{3}{*}{$\begin{array}{l}\text { Recomendto } \\
\text { others }\end{array}$} \\
\hline & \multirow{4}{*}{$\begin{array}{l}\text { Bartlett's Te } \\
\text { Sphericity }\end{array}$} & & \multicolumn{3}{|c|}{ Approx. Chi-Square } & & & & \\
\hline & & & \multirow[t]{2}{*}{ df } & \multirow{2}{*}{\multicolumn{2}{|c|}{ df }} & \multirow{2}{*}{\multicolumn{2}{|c|}{66}} & & \\
\hline & & & & & & & & .249 & .648 \\
\hline Contentlikeness & & & \multicolumn{2}{|c|}{ Sig. } & & \multicolumn{2}{|r|}{.000} & .294 & .455 \\
\hline $\begin{array}{l}\text { Likenessofcollectionandv } \\
\text { ariety }\end{array}$ & .458 & .632 & 1.000 & .366 & .440 & .340 & .432 & .231 & .488 \\
\hline Uniqueness & .268 & .337 & 366 & 1.000 & .655 & .503 & .601 & .314 & .285 \\
\hline Communication & .311 & 456 & .440 & .655 & 1.000 & .495 & .566 & .324 & .309 \\
\hline Inspiring & .301 & .364 & .340 & .503 & .495 & 1.000 & .510 & .597 & .326 \\
\hline Attractiveness & .328 & .381 & .432 & .601 & .566 & .510 & 1.000 & .500 & .367 \\
\hline Usefulness & .249 & .294 & .231 & .314 & .324 & .597 & .500 & 1.000 & .253 \\
\hline Recomendtoothers & .648 & .455 & 488 & .285 & .309 & 326 & .367 & .253 & 1.000 \\
\hline
\end{tabular}

Total Variance Explained

\begin{tabular}{|c|c|c|c|c|c|c|}
\hline \multirow[b]{2}{*}{ Component } & \multicolumn{3}{|c|}{ Initial Eigenvalues } & \multicolumn{3}{|c|}{ Rotation Sums of Squared Loadings } \\
\hline & Total & $\%$ of Variance & Cumulative $\%$ & Total & 96 of Variance & Cumulative $\%$ \\
\hline 1 & 4.555 & 37.956 & 37.956 & 3.248 & 27.065 & 27.065 \\
\hline 2 & 1.720 & 14.332 & 52.288 & 2.952 & 24.600 & 51.665 \\
\hline 3 & 1.197 & 9.977 & 62.265 & 1.272 & 10.599 & 62.265 \\
\hline 4 & .844 & 7.033 & 69.298 & & & \\
\hline 5 & .693 & 5.777 & 75.075 & & & \\
\hline 6 & .646 & 5.382 & 80.456 & & & \\
\hline 7 & .576 & 4.802 & 85.258 & & & \\
\hline 8 & .462 & 3.852 & 89.110 & & & \\
\hline 9 & .369 & 3.076 & 92.187 & & & \\
\hline 10 & .355 & 2.958 & 95.145 & & & \\
\hline 11 & .311 & 2.590 & 97.735 & & & \\
\hline 12 & .272 & 2.265 & 100.000 & & & \\
\hline
\end{tabular}


Towards Excellence: An Indexed, Refereed \& Peer Reviewed Journal of Higher Education / Ms. Shweta Singh / Page 226-249

\begin{tabular}{|c|c|c|c|}
\hline Fatated & $m=\mathrm{m}$ & $\begin{array}{l}\text { Watral } \\
\text { comporitit }\end{array}$ & \\
\hline & 1 & $\geq$ & 3 \\
\hline Heptritra & $7:=2$ & & \\
\hline 17Iवugness & .77 & & \\
\hline Mrtacturerpess & $7 x 3$ & & \\
\hline comphumication & 750 & & \\
\hline$L=E T H R=5$ & $6 \theta=$ & & \\
\hline Fecorratidtoothers & & -701 & \\
\hline Eranciassociation & & $=60$ & \\
\hline Shoppingtromsociathed & & -722 & \\
\hline $\begin{array}{l}\text { Likenesesofogllectionamow } \\
\text { ariety }\end{array}$ & .376 & $-6 \theta \theta$ & \\
\hline Contentikeneses & .390 & $-6-19$ & \\
\hline 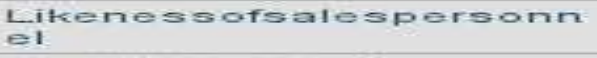 & & & $\mathrm{B} \geq 4$ \\
\hline Frequsticyorvisit & & $-50 \mathrm{~B}$ & 532 \\
\hline
\end{tabular}

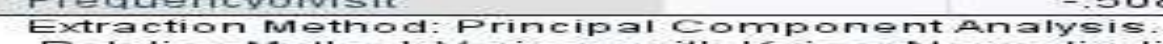
Rotation MEthod: Warimax with Kaiser rormalization.

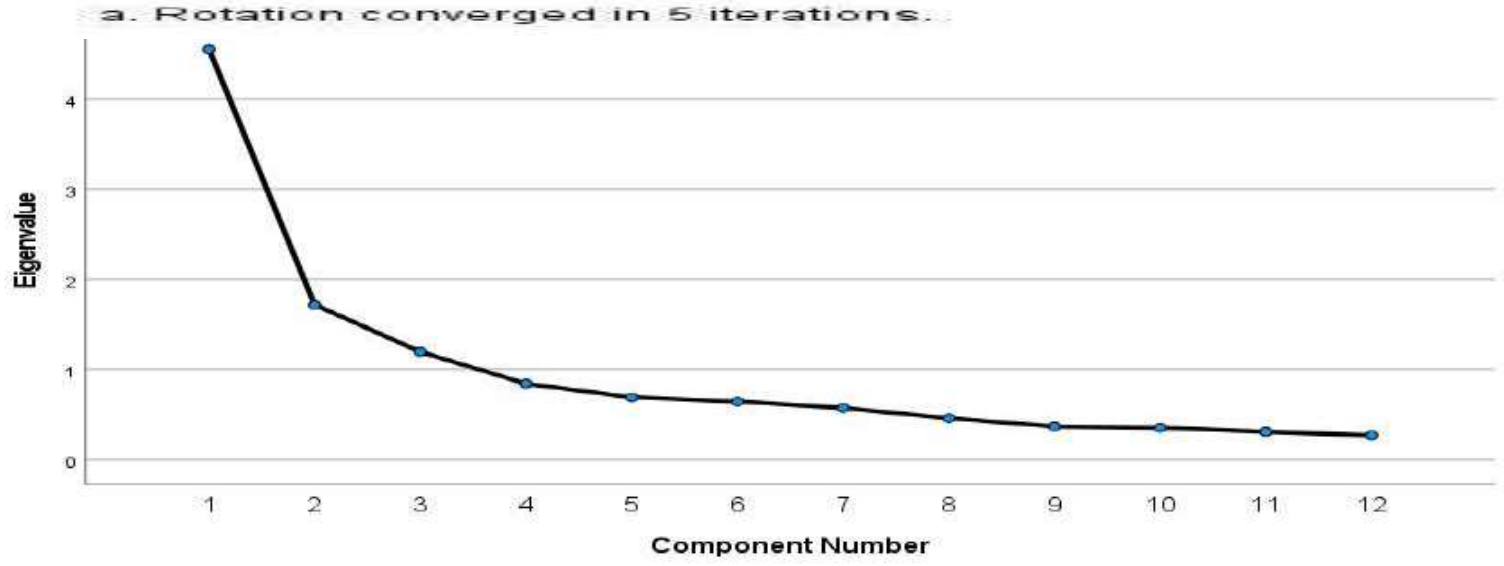

As the number of factors for this test was about 12 items, and then the KMO and Bartlett test value comes out to be 0.836 , which is more than 0.6 , showing that the factor analysis is useful for the data. The Principle Component Method is used to take out the factor with the highest loadings, where it has extracted 3 components which is acceptable, where component 1 has the high loadings (Coefficient correlation), with the eigen values more than the 1 as per the scree plot, and 5 factors in $1^{\text {st }}$ component with correlation coefficients close to 1 are selected for further tests. 
Towards Excellence: An Indexed, Refereed \& Peer Reviewed Journal of Higher Education / Ms.

\section{C) CROSS-TABS}

Shweta Singh / Page 226-249

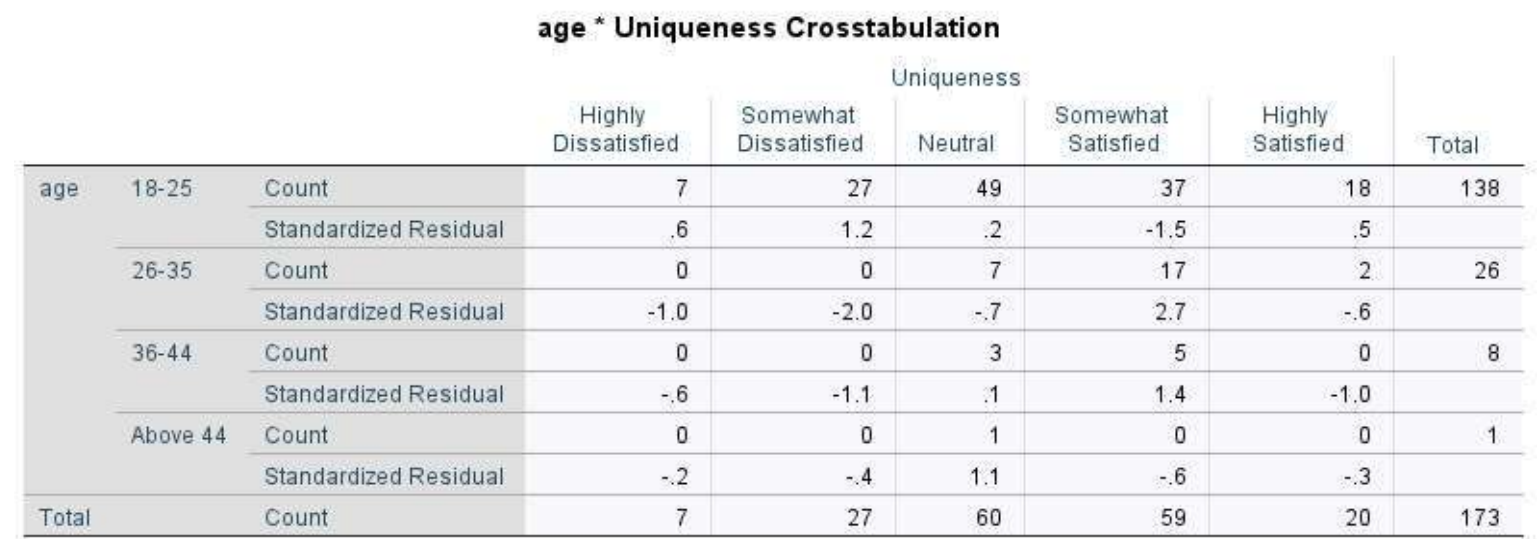

\begin{tabular}{|c|c|c|c|}
\hline \multicolumn{4}{|c|}{ Chi-square Tests } \\
\hline & Value & df & $\begin{array}{c}\text { Asymptotic } \\
\text { Significanco } \\
\text { (2-sided) }\end{array}$ \\
\hline Pearson Chi-square & $23.834^{a}$ & 12 & .021 \\
\hline Likelihood Fatio & 29.815 & 12 & .003 \\
\hline $\begin{array}{l}\text { Linear-by-Linear } \\
\text { Association }\end{array}$ & 4.513 & 1 & .034 \\
\hline Nof Valid Cases & 173 & & \\
\hline
\end{tabular}

\begin{tabular}{|c|c|c|c|c|c|}
\hline \multicolumn{6}{|c|}{ Symmetric Measures } \\
\hline & & Value & $\begin{array}{l}\text { Asymptotic } \\
\text { Standard } \\
\text { Error }\end{array}$ & $\underset{T^{b}}{\text { Approximate }}$ & $\begin{array}{l}\text { Approximate } \\
\text { Significance }\end{array}$ \\
\hline Interval by Interval. & Pearson's R & 162 & .051 & 2.146 & $033^{\circ}$ \\
\hline Ordinal by ordinal & Spearman Eorrelation & 210 & 058 & 2.807 & $.006^{\circ}$ \\
\hline N or Valid Cases & & 173 & & & \\
\hline
\end{tabular}

a. Not assuming the null hypothesis.

b. Using the asymptotic standard error assuming the null hypothesis

c. Based on normal approximation.

The component that was extracted from the component 1, the Cross-Tab as conducted so as to know the variable more related. The factor that the customer opinion as per the Uniqueness of the Social Media Platform of Zara, chi-square had significance value of 0.021 , which is less than 0.05 , means that there is a relationship between the respondents viewpoint about the Uniqueness of social media platform of Brand Zara(dependent) and Age Group(independent) variables.

\section{D) REGRESSION ANALYSIS}


Towards Excellence: An Indexed, Refereed \& Peer Reviewed Journal of Higher Education / Ms. Shweta Singh / Page 226-249

\section{Descriptive Statistics}

\begin{tabular}{l|r|r|r} 
& Mean & Std. Deviation & \multicolumn{1}{l}{$\mathrm{N}$} \\
\hline Uniqueness & 3.34 & 1.007 & 173 \\
\hline age & 1.26 & .567 & 173 \\
\hline
\end{tabular}
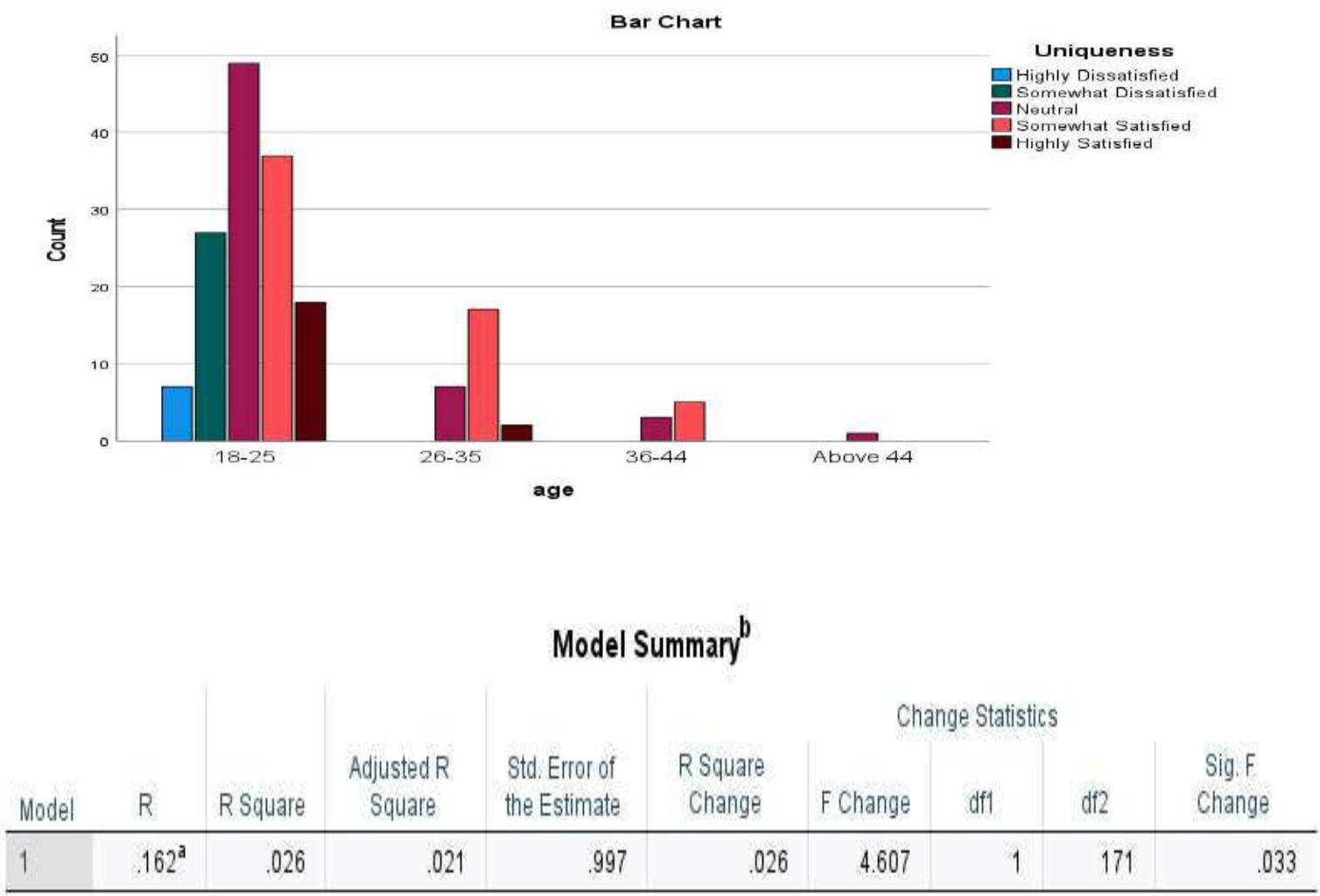

a. Predictors: (Constant), age

b. Dependent Variable: Uniqueness

\begin{tabular}{|c|c|c|c|c|c|c|}
\hline \multicolumn{7}{|c|}{ ANOVA $^{a}$} \\
\hline Madel & & $\begin{array}{l}\text { Sum of } \\
\text { Squares }\end{array}$ & df & Mean Square & $\mathrm{F}$ & Sig. \\
\hline \multirow[t]{3}{*}{1} & Regression & 4.580 & 1 & 4.580 & 4.607 & $.033^{b}$ \\
\hline & Residual & 169.975 & 171 & .994 & & \\
\hline & Total & 174.555 & 172 & & & \\
\hline
\end{tabular}

a. Dependent Variable: Uniqueness

b. Predictors: (Constant), age

To test the association or the impact of one variable on the other, the Regression Analysis test was applied. The significance value (Annova) comes out to be 0.033 less than the 0.05 . Therefore, the null 
Towards Excellence: An Indexed, Refereed \& Peer Reviewed Journal of Higher Education / Ms.

Shweta Singh / Page 226-249

hypothesis will be rejected and alternate hypothesis will be accepted that is "There is a Significant Impact of the Social Media Platforms of the Clothing Brand Zara among the Youth as a growth factor."

\section{E) CORRELATION ANALYSIS}

\begin{tabular}{llrr}
\multicolumn{2}{c}{ Correlations } & & \\
\hline \multirow{2}{*}{ age } & age & Uniqueness \\
\cline { 2 - 4 } & Pearson Correlation & 1 & $.162^{*}$ \\
\cline { 2 - 4 } & Sig. (2-tailed) & & .033 \\
\cline { 2 - 4 } Uniqueness & $\mathrm{N}$ & 174 & 173 \\
\cline { 2 - 4 } & Pearson Correlation & $.162^{*}$ & 1 \\
\cline { 2 - 4 } & Sig. (2-tailed) & .033 & 173 \\
\hline
\end{tabular}

*. Correlation is significant at the 0.05 level (2-tailed).

In order to support my analysis and to show the level of relation between the Uniqueness of social media platforms of Zara and Age Group. The significance value come out to be $0.033(<0.05)$, with 0.162 of moderate positive correlation between these 2 variables. With moderation positive correlation and high significance level it means that there is enough evidence to suggest that correlation we have observed does exist in the population, therefore, alternate hypothesis is accepted "There is a Significant Impact of the Social Media Platforms of the Clothing Brand Zara among the Youth as a growth factor."

\section{F) MULTIPLE RESPONSE ANALYSIS BY CROSS-TAB}

\begin{tabular}{|c|c|c|c|c|}
\hline & & \multicolumn{2}{|c|}{ Responses } & \multirow{2}{*}{$\begin{array}{c}\text { Percent of } \\
\text { cases }\end{array}$} \\
\hline & & $N$ & Percent & \\
\hline \multirow[t]{6}{*}{ \$q. $3^{\circ}$} & age & 139 & $33.3 \%$ & 80.39 \\
\hline & Prices & 130 & 31.196 & 75.196 \\
\hline & Quality & 10 & 2.496 & $5.8 \%$ \\
\hline & variety & 58 & $13.9 \%$ & $33.5 \%$ \\
\hline & Sorvices & 33 & 7.996 & 19.196 \\
\hline & Easyavallability & 48 & $11.5 \%$ & 27.796 \\
\hline Total & & 418 & $100.0 \%$ & $241.6 \%$ \\
\hline
\end{tabular}


Towards Excellence: An Indexed, Refereed \& Peer Reviewed Journal of Higher Education / Ms.

\section{Shweta Singh / Page 226-249}

Gender $\$$ q.3 Crosstabulation

\begin{tabular}{|c|c|c|c|c|c|c|c|c|c|}
\hline & & & \multicolumn{6}{|c|}{$\$ q .3^{\mathrm{a}}$} & \multirow[b]{2}{*}{ Total } \\
\hline & & & age & Prices & Quality & Variety & Services & $\begin{array}{c}\text { Easyavailabili } \\
\text { ty }\end{array}$ & \\
\hline \multirow[t]{2}{*}{ Gender } & Female & Count & 125 & 112 & 9 & 54 & 28 & 45 & 153 \\
\hline & Male & Count & 14 & 18 & 1 & 4 & 5 & 3 & 20 \\
\hline Total & & Count & 139 & 130 & 10 & 58 & 33 & 48 & 173 \\
\hline
\end{tabular}

Percentages and totals are based on respondents.

a. Dichotomy group tabulated at value 1 .

\begin{tabular}{|c|c|c|c|c|c|c|c|c|c|}
\hline \multicolumn{10}{|c|}{ Crosstabulation } \\
\hline & & \multicolumn{8}{|c|}{$\$ q .3^{a}$} \\
\hline & & & age & Prices & Quality & Variety & Services & $\begin{array}{c}\text { Easyavailabili } \\
\text { ty }\end{array}$ & Total \\
\hline \multirow[t]{4}{*}{ age } & $18-25$ & Count & 139 & 98 & 10 & 47 & 25 & 39 & 139 \\
\hline & $26-35$ & Count & 0 & 24 & 0 & 8 & 6 & 7 & 26 \\
\hline & $36-44$ & Count & 0 & 7 & 0 & 3 & 2 & 1 & 7 \\
\hline & Above 44 & Count & 0 & 1 & 0 & 0 & 0 & 1 & 1 \\
\hline Total & & Count & 139 & 130 & 10 & 58 & 33 & 48 & 173 \\
\hline
\end{tabular}

a. Dichotomy group tabulated at value 1

As per the analysis of Multiple-Response Question, frequency and cross-tab is conducted. The Frequency Table indicates each response and case-wise percentage for each option selected by the respondents. Further conducting the Cross-tab on the variables defined both as per Age and Genderwise. As per age the age-group of 18-25 years thinks that the brand needs to improve on its Prices, followed by its Variety. As per Gender category maximum female want improvement in prices, variety and easy availability as well.

\section{* DATA ANALYSIS}

H1- There is a Significant Impact of the Social Media Platforms of the Clothing Brand Zara among the Youth as a growth factor.

In order to fulfil the gaps found in the earlier research papers, this research was conducted with around 175 respondents having around $88.6 \%$ as female respondents and rest male, with age group maximum belonging to the category of "18-35" years of age as students, followed by "26-34" age group. Also, about $68 \%$ respondents think that brand is good in terms of the quality it provides, considering the $\mathrm{H} \& \mathrm{M}$ as its major competitor. It is also found that according to the people brand needs to improve mainly on its prices, and variety.

The tests conducted like the reliability tests that Cron Bach's Alpha value as 0.847(with 9 items), indicating a good internal consistency, as it is close to 1 . Then after conducting the Factor Analysis with around 12 items it was reduced to 3 components as per the rotated component matrix, where 1st component had the highest loading with 5 factors having correlation coefficients close to 1 . The KMO and Bartlett's Test for 12 items had a score of more than 0.836, showing that the data is good fit to proceed further with Factor Analysis. Considering the Eigen Values there are 3 components having values more than 1 , which is good. Then conducting the Cross-Tab (Chi-square) to know the level of relationship on those 5 factors, the Opinion of the Respondents about the Zara's Social Media Platforms in terms of its Uniqueness (Dependent), and Age Group (Independent), had the significance 
Towards Excellence: An Indexed, Refereed \& Peer Reviewed Journal of Higher Education / Ms.

Shweta Singh / Page 226-249

value of 0.021 (less than 0.05), means that we can proceed further to apply the test with these dependent and independent variables. Then applying Regression Analysis to know the level of impact and influence the variables have on each other had significance value of 0.03 (less than 0.05 ), with the opinion of the respondents about Uniqueness of the Zara's social media platforms as dependent, and Age Group as its independent variables, therefore, Alternative Hypothesis is Accepted "There is a Significant Impact of the Social Media Platforms of the Clothing Brand Zara among the Youth as a growth factor". And doing the Correlation Test, to know the strength and direction of relationship between these two factors the significance 0.03 which is significant with Correlation of +0.162 that is considered as Moderate Positive Correlation, meaning that there is enough evidence to suggest that correlation we have being observed does exist in the population, hence, alternate hypothesis is accepted. Therefore, with the help of these tests the Null Hypothesis is Rejected "There is no Significant Impact of the Social Media Platforms of the Clothing Brand Zara among the Youth as a growth factor", and Accept the Alternate Hypothesis that is "There is a Significant Impact of the Social Media Platforms of the Clothing Brand Zara among the Youth as a growth factor". Lastly, after running the Cross-Tabs for the Multiple-Response Question, it can be analysed that respondents especially the Women between the Age Group of 18-25 Years, mainly want the brand to improve in terms of its Prices, and then followed by the Variety in the same category.

H1 - There is a Significant Impact of the Supply Chain Management as growth factor for the Clothing Brand Zara.

Now, taking the 1st Objective into consideration which is based on the secondary data mainly on the Literature Reviews, official website and articles. In the year 2019, the supply chain comprised a network of 1,9851 suppliers, which worked with 8,155 factories providing work to about 2.9 million people. (As per Zara's Official Website) They have also created the "Worker in the Centre 20192022" Programme, which covers the major impact areas. They have standardized process to follow ACT, or Action, Collaboration, Transformation commitments (Zara, n.d.). All supplier product purchase decisions are framed by this particular sustainability criteria. Hence, this means that the buyer cannot order from any supplier until that supplier has passed an initial audit certifying compliance with the requirements laid down in their Code of Conduct. They have created local workplaces, or the clusters including from workers, to government and communities, and work with the 12 clusters accounting for $96 \%$ of their production. The following are the number of audits: 2,789 - Pre-Assessment Audits, 6,411 - Social Audits, 1,619 - Special Audits, and 1,396 - Traceability Audits.

This research was done by collecting the Literature Reviews, articles, and relevant books as well. Ensuring all the activities runs smoothly is what Zara does its best, that is controlling more of its manufacturing and supply chain than other competitive counterparts. It even revealed many factors like the vertical integration, inventory management, the just-in-time production, centralized logistics under its Supply Chain Management. (International Journal of Innovative Science and Research Technology, 2017) on Comparative Study of Supply Chain Management Off-cast Fashion Giants: Zara \& H\&M, also stated for Zara that reacting to the customer's wishes that is of its competitive advantage, and in addition to that, it also maintains much closer relationships with its suppliers that ensures lower prices of both raw materials as well as controls the cost. Zara is even able to manage to respond to the constant changing trends. Some of the industry's most successful fast fashion retailers like these Zara and H\&M keep their products constantly on move with the current trends and 
Towards Excellence: An Indexed, Refereed \& Peer Reviewed Journal of Higher Education / Ms.

\section{Shweta Singh / Page 226-249}

a balanced level of inventory to minimise inventory losses and thereby, maximise profits by maintaining close relationships with the suppliers. The quick response supply chains help them to move their goods from design to distribution in a short period of time. So, in comparison, Zara has built a supply chain that allows them to be updated with latest fashion trends and deliver goods in much less time.

Super Responsive Supply Chain: The Case of Spanish Fast Fashion Retailer Inditex-Zara by (International Journal of Business and Management, 2018) The case study research approach was also adopted, a type of qualitative research method that has planned seasonal product and even started to create much smaller collections more frequently, where all this has been facilitated by developing and establishing their super-responsive supply chain called as the Rapid-Fire Fulfilment, with the ability to compress the product design, production and delivery-cycle lead time within 15 days. Hence, each store is sent about 25,000 units within a 2-week span. Zara owns the product development department and have access to POS data collected from each retail stores. It is able to customize its sourcing strategy as per the demands, and performs the capital-intensive works in-house, and rest outsources the labour-intensive processes to other local contractors. It even has its own distribution networks where the products are delivered regardless of its origin on time. They are able to reduce the "bullwhip effect", and Zara's smooth management of merchandise supply to such stores combined with such enhanced design, affordable price and speed contributes further to its successful strategic consumer behaviour which as a result significantly improves the inventory turns and lowers losses occurring from unsold inventory, this contributes to lower inventory backlogs, and to avoid inventory stock out. Certain studies were limited to a single case study for which findings cannot be generalized properly. Thus, further validation is called for by making large scale survey upon apparel retailers.

Zara mainly uses the fastest mode of transportation that is Planes, and Trucks, they even own Railway tracks. Therefore, Zara, the leading firm in the Apparel Industry and also the youngest one, is spread across 96 countries with around 2200 stores. ZARA owns its entire production activities and is solely responsible for its outcomes whereas, competitor brand H\&M outsources its production activities to other suppliers having high chances of delay in the production process. Zara collaborates with its partners by providing the needed technology, logistics and financial support too. Zara uses the fastest mode of transportation to get first mover advantage whereas H\&M focuses more on cost-cutting and therefore, uses the cheapest mode of transportation, thus reducing the chances of getting the advantage. (Manvinder Singh Rathore, 2019) on Fast Moving H\&M: An Analysis of Supply Chain Management by Business Studies and Social Sciences. The H\&M has its entire focus on price of the product whereas Zara focuses on the customer value. So, only selling the product that is comparatively cheaper does not create much value for customers, but actually the product available at right place, at right time with right quantity and this strategy is well adopted by Zara. Most of the Zara stores are located in those areas which attracts more loyal customers. When H\&M's supply chain when compared to Zara, it has more significantly been successful in its supply chain operations, having distinctive competitive edge over H\&M's supply chain management.

On Supply Chain Management Strategies for Increasing Productivity and Satisfying Customer Demand in the Fast Fashion Retail Sector by (Huatuco, 2019), mentions Zara's supply chain strategies are likely to work well with the results where few respondents, stated that they would like to see new item monthly and some to see new items weekly as well, with good SCM strategies like quick response. It is also found that Zara's parent group Spanish Inditex divides their production into some specialised activities, and each activity is located where it can highly contribute directly to the value of the product. The research methodology for this research is done by quantitative analysis of a 
Towards Excellence: An Indexed, Refereed \& Peer Reviewed Journal of Higher Education / Ms.

Shweta Singh / Page 226-249

questionnaire among customers, supported by secondary data from fast fashion retail company's websites and other publications Therefore, this results in building strong capabilities and increase the customer satisfaction within the UK apparel industry, and to create competitive advantage. Even the Marks and Spencer's clothing inventory is usually high due to third party's supplier, as they do not own manufacturing units, while Zara's manufacture their products as required and minimising the waste. So, the Zara's business model and its SCM strategies are linked together to improve the productivity and aims to provide new product within 2 weeks span in order to compete in the market. Talking about Marks and Spencer's does not have in-house production rather they have various suppliers, as they struggle to cope with short-lived product and will not be as efficient as Zara's to deliver product within a week or two. There were certain limitations as well like the sample size could be increased for the purpose of conducting the research on a larger scale in future now. Furthermore, it should be noted that the researchers can even specify a company for the purpose of analysis and evaluation of their supply chain management.

(Zara's Unique Business Model is Driven by Its Supply Chain Capabilities, 2020) by mhugos, it stated that the heart of the company and its supply chain is a huge and highly-automated distribution centre (DC) called as "The Cube". They adopt a strategy that by creating short production runs makes scarcity of given designs and that a sense of urgency and reason to buy those last supplies. The fabric manufacturers can make quick deliveries of all bulk quantities of fabric directly to the Zara DC, that is the Cube. Although, such a fast-moving supply chain of Zara's constantly requires the attention to keep it running smoothly always. Also, no other competitor can easily copy its effective business model of supply chain, as it is composed of such well-trained people, process, and technology, that even the latest and greatest technology does not provide that competitive advantage all by itself. This brand has spent more than around 30 years to build this unique real-time supply chain. Therefore, the competitors have to do a lot of learning to create such models, and then come out with the efficient operating procedures that is needed to work like Zara is doing. Thereby, supporting my Alternate Hypothesis that "There is a Significant Impact of the Supply Chain Management as a growth factor for the Clothing Brand Zara".

\section{* KEY-FINDINDS}

1) The maximum responses were collected from the female respondents $(88.6 \%)$, with the age group of mainly $18-25$ years $(80 \%)$, and $26-35$ years $(14.9 \%)$.

2) Around $68 \%$ of the respondents like Zara on the basis of its Quality, followed by the collections with $26.3 \%$.

3) The main competitors of Zara as per many respondents are the H\&M (61.1\%), and Marks and Spencer's with the $19.4 \%$.

4) As per age the age-group of 18-25 years including thinks that the Zara needs to improve on its Prices (76.6\%), followed by its Variety (33.1\%), and want improvement in easy availability (28\%) as well.

5) It is found that around more $26 \%-30.3 \%$ of the respondents are able to relate themselves, and more than $11.4 \%$ highly able to relate themselves to content that is being shared on the social media platforms of the brand Zara. 
Towards Excellence: An Indexed, Refereed \& Peer Reviewed Journal of Higher Education / Ms.

Shweta Singh / Page 226-249

6) Around between $24 \%-36 \%$ respondents are somewhat satisfactory with the content shared on the social media platforms of Zara, and more than $15 \%$ are highly satisfied.

7) Around $44.6 \%$ of the respondents are neutral towards shopping via the social media, whereas $42.3 \%$ are sure to shop from the social media platforms of Zara.

8) It was found out that the respondents like the social media platforms of Zara to be more unique, as a mode of communication, attractive and even inspiring.

9) Around $8.6 \%-21.7 \%$ respondents are somewhat likely to recommend the brand Zara to other, and around $60 \%$ are very likely to recommend the brand to others.

10) As per the secondary data, in comparison to other brands, Zara has built a supply chain that allows them to be updated with latest fashion trends and deliver goods in much less time.

11) The Zara's supply chain is a huge and highly-automated distribution centre (DC) called as "The Cube". They adopt a strategy that by creating short production runs makes scarcity of the designs.

12) The productivity of Zara is usually enhanced by aiming to provide new product within 2 weeks span in order to compete in the market, as compared to its competitors as the brand has its own inhouse centralized production facility.

\section{* DISCUSSION}

The research is conducted on the analysis of the supply chain and social media platforms as growth factors of the Zara that gave many new insights and explorations. The need for the research was aroused because of the need to explore the new aspects related to the brand like their minimal marketing aspects and to have analysis of various factors within social media platforms too. The main objective hence was to explore for its efficient supply chain management as well as its successful social media platforms as its main factors for its growth to explore more as these specific were not covered by the earlier researches. So, for this purpose both the primary and secondary approach for the data collection was adopted. The data was also collected data from them via the social media itself as they are directly following the brand and can give proper information needed to conduct the data. But instead it was done by looking into the previous research done in the form the earlier research papers as Literature Reviews, few Articles as well as its own official website, where they have actually described properly all about its supply chain management. Many factors within the social media platforms as well were found like its level of association, likeness towards the content in terms of the uniqueness, inspiration, usefulness, communication, if respondent's wants to shop and file complaints via the social media platforms and many more (as per primary data). Zara is known for its promotional strategies not by its advertisements, thereby, spending minimal amount on the direct promotional strategies as per previous research journal. But, to maintain its position in the long the brand may need to indulge in the advertisement in such a competitive scenario today that exist. For the secondary research the constraint will remain same about its data collection, still has unique understanding of how its supply chain works effectively as compared to its competitors like the H\&M, and Marks and Spencer's, therefore, still remain to be successful with its proper management and coordination among its staff. Therefore, one can find its various features of Zara's supply chain like its agility, justin-time approach, centralized approach, quick and real-time response to the changing trends, also more customer-centric etc., and also social media platforms including the influencers, bloggers help the brand to reach to the top, and to maintain its position from many years as compared to its 
Towards Excellence: An Indexed, Refereed \& Peer Reviewed Journal of Higher Education / Ms.

Shweta Singh / Page 226-249

competitors as per previous research. As per the earlier papers as well the brand also makes effective use of the holograms, and their trained sales staffs to enrich overall customer experiences. This brand has spent more than around 30 years to build this unique real-time supply chain. This research paper can be of great relevance for the future researchers to have more in-depth knowledge. This research paper is helpful in filling those gaps that were found in the earlier research papers, and is even helpful for the future research for both supply chain, as well as the social media platforms of Zara responsible for its growth, not only to find loopholes, but, even to improve in these areas.

\section{* $\quad$ RECOMMENDATIONS}

The research paper had some of the limitations as well. Both certain recommendations, and suggestions for the future researchers as well as for the company are made that can be looked upon in the future as well: -

A) The Brand needs to look after the issues like related to its prices, more collections as well as in relation to its easy availability of the showrooms in the areas, where it does not have its stores. For this purpose, they can think of its further expansion in the near future.

B) The Minimal Advertisement aspect may not work in every scenario, in every situation in such a complex, and competitive world, where its rival fashion retail brands are engaged in heavy direct advertisements, therefore, they can think of involving themselves in the direct advertisement as well, so as to maintain their position in the future as well.

C) The brand may also work on its social media platforms to make it more convenient for its customers to shop via the social media platforms, as many respondents are likely to shop from them.

D) The brand can work more on their content part, that is making content as per the perception, and cultures of various countries.

\section{* CONCLUSION}

On the basis of the analysis done and the findings it can be concluded that the growth of the Zara brand has the factors that is its social media platforms, as well as its efficient supply chain management, which was on the basis of the both primary and secondary data conducted. It can also be said that respondents especially the young women find themselves associated with the content shared on social media platforms of Zara. Respondents, especially, women would also like to shop from the social media platforms as well. The respondents like the content shared on the social media platforms, and find the social media platforms to be more unique, as a mode of communication, attractive and even inspiring as compared to other brands. The supply chain management of the brand is flexible, lean and agile, centralized, customer-centric, just-in-time, and are even able to respond effectively to the changing trends. Therefore, the brand is able to enrich the overall customer experience, maintain their loyalty towards the customers, and their position as the leading fashion retail brand as compared to its competitor's. The brand and other researcher's will be able to understand the customer's needs more properly, and they can further improve to cater to needs of the customers mainly from its social media platforms. 
Towards Excellence: An Indexed, Refereed \& Peer Reviewed Journal of Higher Education / Ms.

\section{* LIMITATIONS}

Shweta Singh / Page 226-249

1) The secondary data collected for the study of supply chain of Zara, as it was a constraint for not being able to directly collect from the suppliers of the Zara.

2) Certain research papers were not easily accessible for the proper study.

3) There were less research papers available studying about social media platforms of the Zara indepth.

4) When the research includes the part based on the secondary data, it is voluminous, and lengthy and may lead to time consumption, while doing analysis and interpretation.

* FUTUTRE RESEARCH DIRECTION: -

A) More Secondary Research can be done for social media platforms.

B) Getting to the relevant Research Papers.

C) Collecting Primary data for the supply chain.

\section{References}

BIBLIOGRAPHY ARTEMIOU, A. (2019). Does having technology in a business enhance or hurt their chances for success?" The implementation of technology in business should be made on the example of ZARA.

Huatuco, H. K. (2019). Supply Chain Management Strategies for Increasing Productivity and Satisfying. BAM Conference.

International Journal of Business and Management. (2018). Super Responsive Supply Chain: The Case of Spanish Fast Fashion.

International Journal of Innovative Science and Research Technology. (2017). (2017 International Journal of Innovative Science and Research Technology- Comparative Study of Supply Chain Management Off-cast Fashion Giants: Zara \& H\&M).

Irma Shyle and Flutura Gjana. (2014). Zara among fast fashion brands.

Joseph, N. (2015). Integrated Marketing Communications - Communication Portfolio on ZARA.

Kato, V. (2018). Analysis of the Keys to Zara's (Inditex) Successful Business Model.

Manvinder Singh Rathore, K. M. (2019). Fast Moving H\&M: An Analysis of Supply.

moneycontrol. (2020, July). Retrieved from moneycontrol.com.

Roederer, U. M. (2016). Zara: The international success of fast-moving fashion.

The role of market orientation on company performance through the development of sustainable competitive advantage: The Inditex-Zara case (2003). 
Towards Excellence: An Indexed, Refereed \& Peer Reviewed Journal of Higher Education / Ms. Shweta Singh / Page 226-249

Viardot, E. (2013). How zara has revolutionized the fashion industry and become a worldwide leader.

Zara. (n.d.). Retrieved from Zara India.

Zara - Marketing Plan.

ZARA CASE STUDY (2002).

Zara's Unique Business Model is Driven by Its Supply Chain Capabilities (January 2020).

ZARA-Case Study Analysis (2015).

Ms. Shweta Singh, Marketing (2019-2021)

ORCID ID 0000-0002-4548-1309

Bimhrd, Sri Balaji University, Pune

8966972355, singh.shweta08@yahoo.in 